Revista de

Contabilidade e

Organizações

www.rco.usp.br
DOI: http://dx.doi.org/10.11606/rco.v11i29.126312
Journal of

Accounting and

Organizations

www.rco.usp.br

\title{
A visão do controle externo na eficiência dos gastos públicos com educação fundamental
}

\author{
Klerton Andrade Freitas de Amorima; Josedilton Alves Diniz ${ }^{\mathrm{a}}$; Severino Cesário de Lima ${ }^{\mathrm{b}}$ \\ ${ }^{a}$ Universidade Federal da Paraiba \\ ${ }^{b}$ Universidade Federal do Rio Grande do Norte
}

\section{Informações do Artigo}

Histórico do Artigo

Recebido: 08 de fevereiro de 2017

Aceito: 11 de maio de 2017

Palavras-chave:

Pareceres de Julgamento de Contas.

Eficiência.

Tribunal de Contas.

\begin{abstract}
Resumo
A presente pesquisa teve por objetivo analisar se a eficiência técnica na aplicação dos recursos públicos dos municípios paraibanos relaciona-se com os pareceres de julgamento de contas municipais emitidos pelo TCE-PB. Para tanto, definiu-se a hipótese de que existe relação positiva entre os pareceres de julgamento de contas dos municípios emitidos pelo TCE-PB e o nível de eficiência técnica na aplicação dos recursos públicos na educação fundamental. Para o desenvolvimento da pesquisa escolheu-se como caso concreto os 223 municípios integrantes do Estado da Paraíba com dados compreendendo o período de 2009 a 2011. Os escores de eficiência foram obtidos no portal web do TCE-PB. Para testar a hipótese utilizou-se a regressão logit. Com base nos achados empíricos, não se rejeita a hipótese de pesquisa, validando-se que, de alguma forma, o parecer do TCE-PB enxerga a dimensão da eficiência dos gastos públicos com educação fundamental nas apreciações das contas de gestão dos municípios.
\end{abstract}

Copyright (C) 2017 FEA-RP/USP. Todos os direitos reservados

\section{INTRODUÇÃO}

O controle externo no âmbito das instituições governamentais é de competência constitucional das Cortes de Contas. No artigo 70 da Constituição Federal de 1988 (CF/88) e por intermédio da Ementa Constitucional $n^{\circ}$ 19 de 1998 (EC n 19/98) foi delineada a missão do Tribunal de Contas, que consiste na "fiscalização contábil, financeira, orçamentária, operacional e patrimonial dos entes e das entidades da administração direta e indireta, quanto à legalidade, legitimidade, economicidade, aplicação das subvenções e renúncia de receitas".

Os aspectos ligados à legalidade e à legitimidade têm sido o principal alvo da atuação dos Tribunais de Contas no controle dos gastos públicos. A análise, na maioria das vezes, tem se restringido à verificabilidade do alcance dos limites legais nas despesas condicionadas à legalidade e à comprovação das despesas executadas pelos gestores públicos.

As dimensões de eficácia, eficiência e efetividade dos gastos são responsáveis por garantir o êxito da ação estatal, buscando maximizar os resultados e minimizar os custos, ou seja, utilizando os recursos da maneira mais inteligente possível. A efetividade na ação pública vem corroborar de forma mais democrática, oportunizando transparências e responsabilidade em relação aos benefícios trazidos para a sociedade como um todo (Torres, 2004).

O Princípio da eficiência expresso no artigo 37 da $\mathrm{CF} / 88$, por meio da $\mathrm{EC} \mathrm{n}^{\circ} 19 / 98$, determina que na administração direta e indireta os gestores e demais responsáveis pela utilização de recursos públicos devem dar criteriosas satisfações ao interesse coletivo. Esse corolário foi reforçado pela Lei Complementar 101, denominada Lei de Responsabilidade Fiscal (LRF), ao estabelecer que a conduta dos gestores deve estar voltada para uma administração responsável, exigindo aplicação dos recursos públicos de forma planejada, econômica e financeiramente equilibrada; os custos e resultados devem estar presentes em todo procedimento administrativo. Assim, o velho paradigma de que "gastar mais é necessariamente melhor" vem sendo substituído pela ideia que enfatiza o produto do gasto relativamente a seu custo, ou seja, o gasto com qualidade.

Autor Correspondente: Tel (83) 3216-7200

E-mail: klertonandrade@gmail.com (K. A. F. Amorim); josedilton@gmail.com(J. A. Diniz); cesario@ufrnet.br (S. C. Lima)

UFPB - Cidade Universitária, s/n - Castelo Branco III, João Pessoa - PB, 58051-900, Brasil. 
Assim, o art. 37 da Constituição federal estabelece que é dever da administração pública obedecer a vários princípios, dentre eles, o princípio da eficiência, quando executarem atos de gestão. Adicionalmente, o art. 74, nos incisos II e IV, estabelece que o sistema de controle interno deve avaliar os resultados de gestão, observando-se o cumprimento dos princípios da eficiência e eficácia e, suplementarmente, apoiar o controle externo. Assim, depreende-se que o controle externo, ao julgar as contas jurisdicionadas, além de observar a legalidade, legitimidade e economicidade, deve certificar-se de que os resultados de gestão foram alcançados com eficiência e eficácia.

Como forma de romper este paradigma e outorgar maior efetividade ao controle dos gastos públicos, apresenta-se nesse trabalho a propositura de uma abordagem sobre a mensuração da eficiência dos gastos públicos municipais, utilizando o conceito de fronteira eficiente, que consiste na evidenciação de um diagnóstico público acerca da capacidade dos gestores em converter os recursos públicos em produtos e resultados de interesse coletivo.

Desse modo, a eficiência é entendida como uma função que otimiza os recursos aplicados nos serviços públicos, bem como os resultados obtidos. Assim, o problema dessa pesquisa pode ser descrito nos seguintes termos: Qual a relação entre o parecer do TCE-PB emitido no julgamento das contas dos municípios paraibanos sob sua jurisdição e o nível de eficiência técnica na aplicação dos recursos públicos na educação fundamental?

Portanto, a presente pesquisa tem por objetivo analisar a eficiência técnica na aplicação dos recursos públicos com educação fundamental dos municípios paraibanos, verificando se existem relações positivas com os pareceres de julgamento de contas municipais emitidos pelo TCE-PB.

Estabelecidos o problema e o objetivo da pesquisa, definiu-se a seguinte hipótese norteadora do estudo: existe relação positiva entre o parecer do TCE-PB emitido no julgamento das contas dos municípios paraibanos e o nível de eficiência técnica na aplicação dos recursos públicos na educação fundamental. A definição dessa hipótese tem por finalidade oferecer, conforme grifado por Martins e Theóphilo (2007), o direcionamento do percurso da pesquisa, a fim de estabelecer explicações ou soluções suscetíveis.

A contribuição do presente estudo consiste em demonstrar para os gestores públicos, para os órgãos de controle externo e para a sociedade em geral a importância da avaliação de resultados de gestão com foco na aplicação eficiente dos recursos públicos que propicia o cumprimento dos limites constitucionais de aplicação de recursos em educação e, por conseguinte, a aprovação das contas dos gestores públicos.

\section{REFERENCIAL TEÓRICO}

\subsection{Avaliação de desempenho de entidades do setor público}

O papel principal do Estado é agir de modo a maximizar o bem-estar da população e os níveis de desenvolvimento socioeconômico de suas localidades. Nesse sentido, os governos locais são responsáveis pela provisão de uma série de bens cuja oferta não é realizada de forma suficiente pelo mercado (Samuelson,1954). Para isso, a sociedade disponibiliza ao Estado os recursos mediante tributos arrecadados para financiamento da máquina estatal e para o fornecimento de bens e serviços a sociedade.

O atendimento a essas necessidades da população não necessariamente faz com que os governos despendam uma grande quantidade de recursos públicos. Pelo contrário, deve-se levar em conta a natureza limitada desses recursos e como os gestores públicos devem utilizá-los de forma racional, privilegiando a eficiência e a avaliação de desempenho da gestão.

Nesse sentido, Heinrich (2003) assinala que a avaliação de desempenho deve ser capaz de ajudar os gestores públicos a entender como suas políticas e decisões gerenciais estão ligadas aos resultados obtidos e quais fatores internos e externos podem restringir ou intervir no seu desempenho.

Segundo a literatura sobre medidas de desempenho (performance measurement), os indicadores de eficiência e eficácia são os principais mecanismos de avaliação utilizados para medir o desempenho da gestão governamental e, consequentemente, proporcionar accountability (Callahan, 2003; Haas, 2003; Julnes, 2003; Ammons, 2003; Oliveira \& Turrioni, 2006). Esses indicadores promovem a oportunidade para responder questões levantadas pelos cidadãos, tais como: a criminalidade está aumentando? Qual o desempenho das crianças na escola? Quais os resultados dos programas de saúde? O governo está atingindo as metas previstas para educação? 
De acordo com Pacheco (2009) existem diversos problemas nos indicadores de mensuração de desempenho; contudo, a contribuição que eles oferecem à avaliação da gestão, tanto na mensuração de resultados quanto na transparência das informações, auxilia na identificação da efetividade dos resultados produzidos.

Para que os gestores atribuam melhor utilização dos seus recursos disponíveis, deve-se alertar para vários critérios que garantam que o indicador de desempenho seja de maior qualidade, tais como: abrangência, clareza, acessibilidade, comparabilidade, baixo custo, estabilidade, dentre outros, a depender do cenário de avaliação. Logo, a utilização desses critérios na avaliação de desempenho é importante, pois serão visualizados padrões, erros e pontos fortes para correções de suas atividades e processos.

Assim, o Estado tem os instrumentos de planejamento, as técnicas de execução e as formas de controle para que os gastos públicos realmente tenham o condão de fazer com que os recursos públicos sejam aplicados de forma eficiente. Desta forma, para manter o cumprimento da dimensão da eficiência, o controle externo tem como missão observar se os gastos estão sendo aplicados em conformidade com os mandamentos legais da CF/88 e EC n 19/98, bem como se há alocação dos recursos que levem à dimensão da eficiência.

\subsection{A alocação eficiente dos recursos públicos na educação}

A eficiência dos gastos públicos passou por modificações a partir da nova política educacional imposta pela Constituição Federal de 1988. O processo de descentralização das obrigações do estado, apesar de reduzir a autonomia do gestor, conferiu maior flexibilidade na utilização de recursos públicos com a educação, obedecendose aos limites constitucionais impostos, conforme assinala Mendes (2003).

Os reflexos dessas alocações de recursos têm como objetivo aumentar a produtividade, o crescimento econômico e as oportunidades socioeconômicas do país. De acordo com Pritchett e Filmer (1999) pode-se expressar a função da educação por meio da quantidade de produtos gerados para uma possível quantidade de recursos aplicados.

Para estabelecer padrões e eliminar as diferenças sociais existentes, principalmente, na educação básica, o governo criou o Fundo de Desenvolvimento da Educação Básica (FUNDEB) em Remuneração e Valorização do Magistério (RMV) no âmbito de cada estado. De certa forma, o gestor deve aplicar não menos que $60 \%$ dos recursos do FUNDEB para a valorização do magistério. Esses recursos são condicionados principalmente ao ensino básico para gastos com salário dos professores e na qualificação profissional.

A CF/88 também exige dos municípios a aplicação de no mínimo $25 \%$ da receita de impostos e transferências na Manutenção e no Desenvolvimento da Educação (MDE), impondo aos gestores e secretários a utilizar estes recursos de acordo com regras exigidas, bem como aplicar na rede municipal de educação com a finalidade de obter impactos positivos na educação básica.

Discussões realizadas por diversos autores internacionais apresentaram resultados diferentes em relação aos gastos públicos e ao desempenho educacional. Nessa perspectiva, a maior parte dessas discussões surgiu por meio do relatório de Coleman et al (1966), evidenciando-se importantes resultados por intermédio da função de produção ou fronteira de eficiência na educação. Diante disso, Hanushek (1994) levantou várias questões sobre qual é a melhor forma de aumentar o desempenho escolar a partir da alocação de recursos públicos.

Por meio dos resultados encontrados nesse relatório, nota-se que o desempenho educacional não depende somente da alocação de recursos na educação, mas também de outras variáveis, tanto no contexto escolar como nas origens socioeconômicas (Hanushek, 1986). Em vista disso, pode-se destacar que a ligação existe por meio do modo de aplicação dos recursos públicos e de como são direcionados na educação (Diniz, Corrar, \& Lima, 2014).

Outros autores afirmam que a busca de melhoria no desempenho educacional envolve diversos processos. A relação dos recursos monetários e não monetários constitui fator importante no ensino e aprendizagem, uma vez que as relações na escola são essenciais na qualidade do ensino (Dourado, Oliveira, \& Santos, 2007). 


\subsection{Tribunal de Contas sobre a perspectiva da análise da legalidade, da eficiência e da economicidade}

A avaliação dos gestores públicos vem demonstrando importantes conquistas na eficiência sobre a perspectiva do Tribunal de Contas. Neste sentido, Belo (2013) norteia que o controle externo é responsável por reforçar a transparência e a responsabilidade dos gestores, garantindo elevados padrões de trabalho da auditoria como a integridade do sistema financeiro e a confiabilidade das receitas e despesas.

O controle externo é o responsável por avaliar as informações dos gestores, analisando sua gestão a fim de assegurar a precisão das demonstrações financeiras e cumprimento das leis, regulamentos e acordos, e, posteriormente, tirar suas conclusões.

Estes poderes são concedidos de forma autônoma ao Tribunal de Contas. Gualazzi (1992) afirma que o Tribunal de Contas é funcionalmente autônomo. Por ser um órgão administrativo parajudicial, tem a função primordial de controle externo, nos aspectos fáticos e jurídicos sobre a execução financeira-orçamentária. Os TCs abrangem amplas atribuições expressas no artigo 71 da CF/88, tanto nos atos de julgamento, quanto na apreciação para fins de registro e fiscalização de quaisquer recursos repassados aos entes jurisdicionados.

Para Silva e Revorêdo (2005) o controle externo tem avançado na dimensão da eficiência uma vez que os relatórios de auditoria têm retratado os indicadores socioeconômicos como uma forma de induzir os gestores na melhoria da condição de vida da população.

Essa análise tem sido um desafio para as Cortes de Contas por dois aspectos: primeiro, gerou-se a necessidade do desenvolvimento de sistemas eletrônicos específicos para adequação do grande volume de documentos recebidos pelos TCs, contribuindo e viabilizando a padronização, a redução de custos operacionais e a eficiência nos trabalhos técnicos desenvolvidos (Lureiro, Teixeira \& Moraes, 2009); segundo, as cortes de contas, por serem Tribunais, sofrem grande influência do direito positivo, ou seja, a aplicação do direito exacerbadamente ligado aos códigos e as normas escritas (sistema code law).,

De acordo com Weffort (2005), o sistema legal público brasileiro é evidenciado sobre o sistema code law do direito romano, em decorrência da colonização portuguesa. Deste modo, é necessário compreender as duas grandes tradições do direito: o direito romano ou code law, e o direito consuetudinário ou common law. As fundamentais diferenças entre esses dois sistemas estão relacionadas à origem e força da lei. No direito romano, as normas são emanadas em leis; já no direito consuetudinário a origem está ligada mais aos costumes e tradições culturais (Lopes, 2009).

A utilização dos recursos disponíveis para administração dos gestores deve seguir regras constitucionais. Desta maneira, o gestor não só deve focalizar sua perspectiva na legalidade e legitimidade, mas também em outros aspectos relevantes para utilização eficiente dos gastos públicos, posto que a constituição não só delegou ao tribunal a missão de analisar as despesas sobre a perspectiva da legalidade, mas também a economicidade dos atos de gestão pública.

Para tanto, Segundo Herbest (2010), o cumprimento dos limites legais em relação à LRF vem preocupando os gestores públicos. Assim, para evitar punições dos TCs, eles passam a utilizar as informações contábeis somente para atingir a legitimidade de seus atos.

\section{METODOLOGIA}

A presente pesquisa foi conduzida por meio de um estudo descritivo com abordagem de dados quantitativa, utilizando-se de procedimentos estatísticos e não estatísticos, operacionalizados por meio de levantamento de dados. Em apoio à abordagem quantitativa, foi realizado levantamento bibliográfico e documental.

\subsection{Procedimento de coleta de dados}

Para a consecução dos objetivos desta pesquisa, foram escolhidos como caso concreto de análise os 223 municípios integrantes do Estado da Paraíba, no período de 2009 a 2011.Os dados foram colhidos nas seguintes 
fontes:

a) informações contábeis e financeiras no banco de dados do Tribunal de Contas da Paraíba - TCE-PB (www.tce.pb.gov.br);

b) informações educacionais, disponibilizadas pelo Instituto Nacional de Estudos e Pesquisas Educacionais Anísio Teixeira (INEP), pela Secretaria de Educação e Cultura do Estado da Paraíba e pelo Sistema de Avaliação do Ensino Básico (SAEB/INEP);

c) informações relacionadas ao parecer prévio acerca da apreciação da prestação de contas anual dos gestores, obtidas do portal web do TCE-PB (www.tce.pb.gov.br). Para tanto, foi realizada análise documental dos processos de prestações de contas, identificando o tipo de parecer emitido e os percentuais de aplicação em Manutenção e Desenvolvimento do Ensino - MDE e Remuneração e Valorização do Magistério - RVM.

\subsection{Escores de eficiência técnica}

A presente pesquisa coletou os escores de eficiência diretamente do site do TCE-PB (www.tce.pb.gov. br), que foram calculados com auxílio da técnica DEA - Data Envelopment Analysis (Análise Envoltória de Dados), desenvolvida por Charnes et al. (1978). Essa técnica consiste em uma abordagem usada nas comparações de eficiência de unidades produtivas organizacionais com atividades relativamente homogêneas. A DEA é uma técnica de programação matemática para avaliar unidades similares, isto é, que executam a mesma função ou subordinadas a um mesmo órgão controlador. Estas unidades são denominadas unidades de tomada de decisão (decision making units - DMU), que nesse estudo são representadas pelos 223 municípios paraibanos.

$\mathrm{O}$ indicador de eficiência de cada município paraibano (DMU) foi calculado por meio da técnica DEA Sequencial (DEA-S) com adoção do modelo BCC criado por Banker, Chanes e Cooper (1984), com retorno de escala variável, orientado a output.

Os escores de eficiência dos municípios assim obtidos foram utilizados para regredir com as variáveis explicativas do tipo de parecer emitido pelo TCE-PB, descritas adiante. Como forma de situar a maneira como se deu o cálculo da eficiência, descrevem-se abaixo os paramentos utilizados pelo TCE-PB, conforme as notas técnicas do IDGPB (Índice de Desempenho dos Gastos Públicos com Educação na Paraíba), utilizadas para medir a eficiência técnica disponível em http://idgpb.tce.pb.gov.br/.

A fronteira de produção foi estimada a partir do input e dos outputs relativos aos serviços públicos referentes ao Ensino Fundamental (EF) prestado pelos Municípios paraibanos. A função de produção foi composta de um insumo (input) e de dois produtos (outputs) conforme pode ser visto no Quadro 1.

\begin{tabular}{|c|c|c|c|}
\hline Tipo & Variável & Descrição & Fonte \\
\hline Input & $\begin{array}{l}\text { Despesa corrente } \\
\text { por aluno }\end{array}$ & $\begin{array}{l}\text { Total da despesa corrente pela quantidade de } \\
\text { alunos matriculados na rede de EF municipal }\end{array}$ & TCE-PB/IDGPB \\
\hline Output -1 & $\begin{array}{l}\text { Prova Brasil em } \\
\text { Língua Portuguesa }\end{array}$ & $\begin{array}{l}\text { Notas médias de proficiência em Língua } \\
\text { Portuguesa }\end{array}$ & INEP \\
\hline Output -2 & $\begin{array}{l}\text { Prova Brasil em } \\
\text { Matemática }\end{array}$ & Notas médias de proficiência em Matemática & INEP \\
\hline
\end{tabular}

Quadro 1.Variáveis de input discricionário e de outputs do modelo de eficiência técnica Fonte: Elaborado pelos autores.

Essas variáveis são as mais utilizadas em trabalhos que se propõem analisar a eficiência dos gastos públicos na função educação e na subfunção governamental ensino fundamental. Assim, corroborando com as definições propostas, dentre vários trabalhos, referenciam-se Hanushek (1994), Menezes Filho, Amaral (2009) e Diniz, Corrar, Lima (2014). 


\subsection{Teste de hipóteses}

O teste de hipóteses foi realizado a partir da análise de dados categóricos, desenvolvida pela equação de regressão logística, em cross section, similar a um painel em pooling. Foram utilizados dados em painel para enriquecer a análise aplicada uma vez que seria impossível utilizarmos apenas dados temporais (Gujarati \& Porter, 2011), visto que os dados basilares para o cálculo da eficiência (IDEB) são bienais. Hair et al (1998) afirmam que a regressão logística permite a realização de cálculos probabilísticos de ocorrência de um determinado fenômeno em estudo - no caso em estudo, a probabilidade de uma conta municipal ser aprovada ou não pelo TCE-PB dada a eficiência técnica dos gastos no ensino fundamental.

De acordo com Tabachnick e Fidell (1996), o modelo logit é moderadamente livre de restrições, facilitando a utilização de diversos tipos de variáveis, sejam elas contínuas, discretas ou dicotômicas.

O modelo empírico tem a seguinte configuração:

$$
\delta_{i}=\beta_{1}+\beta_{2} \mathrm{EF}_{\mathrm{i}}+\mathrm{MDE}_{\mathrm{i}}+\mathrm{RVM}_{\mathrm{i}}+\mathrm{w}_{i}
$$

Em que:

$\delta_{i t}$ - é variável dummy que representa a decisão do TCE-PB para a prestação de contas anual do município $i$ (o resultado do parecer " 1 " indica situação favorável e "0" indica contrário à aprovação das contas);

$\mathrm{EF}_{\mathrm{i}}$ - escores de eficiência do município $i$ para os serviços de educação básica;

$\mathrm{MDE}_{\mathrm{i}}$ - percentual das aplicações em Manutenção e Desenvolvimento da Educação do município $i$;

$\mathrm{RVM}_{\mathrm{i}}-$ percentual das aplicações na Remuneração e Valorização do Magistério do município $i$;

$\mathrm{W}_{i t}=$ termo de erro da regressão.

As variáveis MDE e RVM funcionam como variáveis de controle da eficiência e a variável dependente é representada pelos resultados dos pareceres. Optou-se por realizar uma regressão cross section empilhada uma vez que o fator tempo não é relevante para o alcance dos objetivos. O que interessa é a posição do TCE-PB na emissão dos pareceres prévios nas contas municipais em relação à eficiência na aplicação dos recursos da educação.

\section{RESULTADOS E DISCUSSÕES}

Nessa pesquisa o universo de estudo foi os 223 municípios integrantes do Estado da Paraíba, utilizandose dados do período de 2009 a 2011. As informações utilizadas foram aquelas de natureza contábil e financeira da educação fundamental, bem como as informações acerca do parecer prévio do TCE-PB sobre a apreciação da prestação de contas anual dos gestores.

Dessa forma, o número de observações foram 664 pareceres prévios, posto que foram excluídos desta análise 5 dados dos municípios por não conterem as informações necessárias para os procedimentos das análises propostas. Os dados foram tabulados e rodados utilizando-se o software estatístico Stata 13. Os dados da eficiência dos gastos em educação referente ao exercício de 2010 foram obtidos mediante interpolação linear, uma vez que os dados basilares para o cálculo da eficiência (IDEB) são bienais publicadas em anos ímpares.

\subsection{Análise descritiva dos dados}

O levantamento descritivo demonstrado na Tabela 1 apresenta os resultados anuais dos pareceres prévios emitidos pelo TCE-PB na apreciação da prestação de contas anual dos gestores municipais do Estado da Paraíba. 
Tabela 1. Julgamentos das prestações de contas anuais dos municípios no TCE-PB

\begin{tabular}{ccccccccc}
\hline Parecer & \multicolumn{2}{c}{$\mathbf{2 0 0 9}$} & $\mathbf{2 0 1 0}$ & \multicolumn{2}{c}{$\mathbf{2 0 1 1}$} & \multicolumn{2}{c}{ Total } \\
\hline Parecer contrário & 65 & $9,79 \%$ & 80 & $12,05 \%$ & 77 & $11,60 \%$ & 222 & $33,43 \%$ \\
Parecer favorável & 158 & $23,80 \%$ & 142 & $21,39 \%$ & 142 & $21,39 \%$ & 442 & $66,57 \%$ \\
Total & $\mathbf{2 2 3}$ & $\mathbf{3 3 , 5 8 \%}$ & $\mathbf{2 2 2}$ & $\mathbf{3 3 , 4 3 \%}$ & $\mathbf{2 1 9}$ & $\mathbf{3 2 , 9 8 \%}$ & $\mathbf{6 6 4}$ & $\mathbf{1 0 0 , 0 0 \%}$ \\
\hline
\end{tabular}

Fonte: Dados da pesquisa.

Como pode-se observar na Tabela 1, foram rejeitadas 222 prestações de contas, representando 33\% das contas apreciadas. Por sua vez, foram aprovadas 442 contas dos 664 julgamentos apreciados, representando $67 \%$. Analisando a Figura 1, sob os períodos investigados, o ano de 2009 foi o período que obteve o maior número de contas aprovadas, apresentando exatamente 158 pareceres favoráveis, constituindo-se o período que obteve o menor número de rejeições. Já em relação ao maior número de contas rejeitadas, o ano de 2010 foi o que mais se destacou, retratando 80 reprovações dos 222 pareceres contrários constatados.

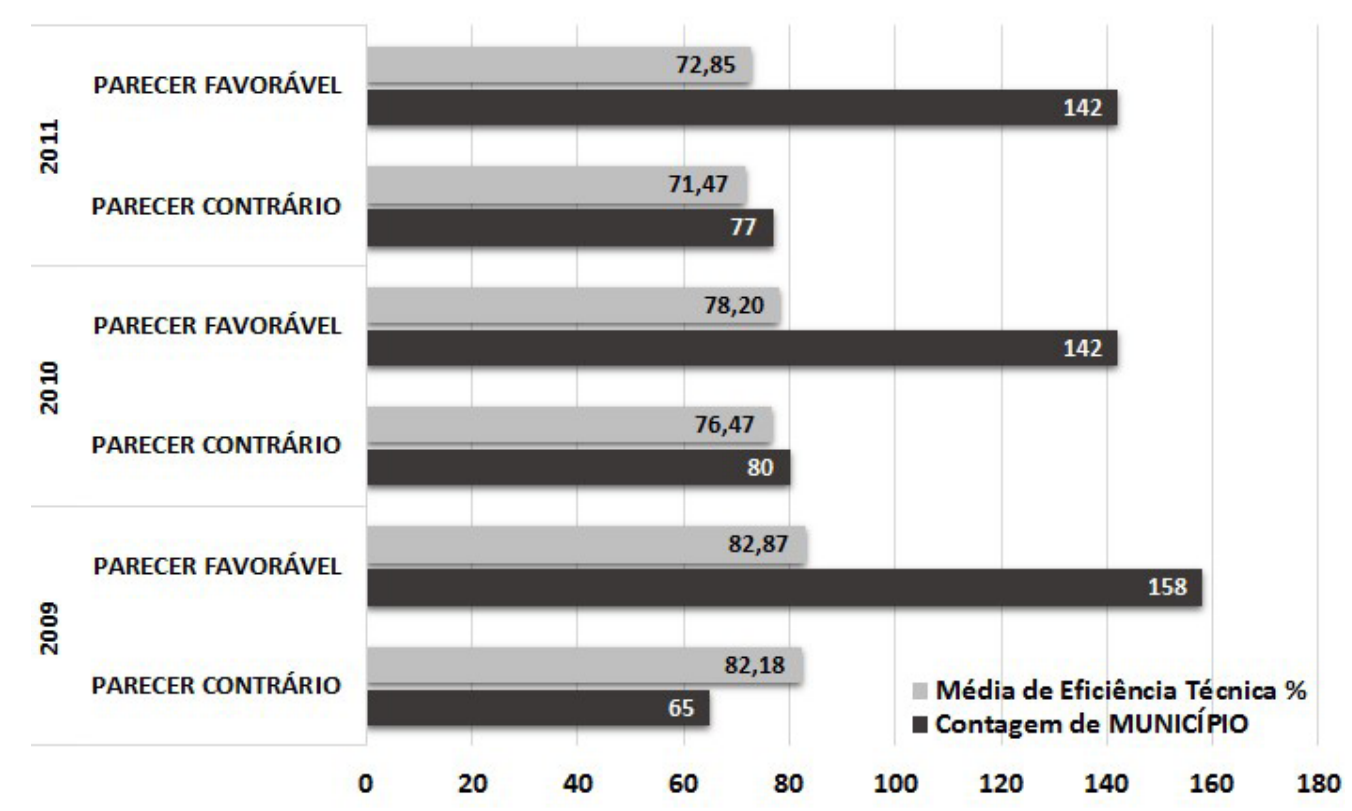

Figura 1. Média de eficiência técnica em relação aos pareceres dos municípios Fonte: Elaborado pelos autores.

A partir da análise da Tabela 2, verifica-se que, de acordo com a prestação de contas anual dos gestores, em média, os municípios alocam 63,93\% dos recursos em RVM, contendo um desvio padrão de 9,23\%.

Tabela 2. Estatística descritiva

\begin{tabular}{ccccc}
\hline Variáveis & Média & Desvio padrão & Mín & Máx \\
\hline RVM & 63,93 & 9,23 & 0,78 & 100,00 \\
MDE & 27,46 & 3,46 & 14,66 & 68,82 \\
Parecer & 0,67 & 0,47 & 0,00 & 1,00 \\
EF\% & 77,57 & 8,63 & 53,96 & 100,00 \\
\hline
\end{tabular}

Fonte: Dados da pesquisa

De acordo com a norma legal, a aplicação em RVM é de 60\%, sendo que na amostra analisada a média alcançou 63,93\%. Já em relação à aplicação dos recursos em MDE, observa-se uma média de 27,46\%, com desvio padrão de 3,46\%. Para as aplicações em MDE, o mínimo constitucional é 25\%. Nessas condições, observa-se, em média, que $67 \%$ dos pareceres do TCE-PB foram favoráveis. Essa constatação fica mais bem justificada pelas probabilidades calculadas para se ter um parecer prévio favorável no modelo probit. 
É possível observar, também, na Tabela 2, que os municípios alcançaram em média 77,57\% de eficiência dos gastos públicos municipais em educação, quando, para ser completamente eficientes, esse escore deveria atingir 100\%. Esses dados relevam que os municípios analisados precisam ser mais eficientes na aplicação dos recursos públicos de educação.

\subsection{Análise do modelo empírico}

Utilizou-se nessa pesquisa o método de regressão binária simples, cujo principal objetivo é a realização de cálculos probabilísticos com a intenção de verificar a chance de ocorrência de um determinado evento - no caso específico, a probabilidade de o município obter um parecer prévio do TCE-PB dada a eficiência técnica dos gastos no ensino fundamental. Este tipo de regressão possui a vantagem de ser mais flexível em relação às outras modalidades de regressão, devido à flexibilidade dos pressupostos exigidos no seu algoritmo.

Segundo Freitas (2013), a função de ligação presente no algoritmo da regressão logit possui como variável dependente uma variável binária (Parecer favorável $=1$; Parecer contrário $=0$ ). Para a realização do cálculo da probabilidade, foram utilizadas funções de distribuições específicas para o modelo; dessa forma, a distribuição logística utilizada foi a normal. Neste contexto, o método da máxima verossimilhança é utilizado para estimar os parâmetros das duas funções de ligação, uma vez que são realizadas transformações das distribuições acumuladas.

$\mathrm{Na}$ estimativa do modelo logit foram necessárias quatro interações e a probabilidade do teste Prob $\left(\mathrm{x}^{2}\right)$ ficou aproximadamente zero, indicando que não se pode rejeitar, com significância de $1 \%$, a hipótese de que todos os coeficientes sejam iguais a zero. De acordo com a Tabela 3, pode-se afirmar, também, que os coeficientes vistos conjuntamente são significativos para explicar a relação entre tipo de parecer emitido pelo Tribunal de Contas e a medida de eficiência do gasto com educação, calculada pelo DEA-Sequencial.

Por outro norte, todos os estimadores do modelo foram significantes, consolidando a consistência do modelo. A Tabela 3 abaixo reflete as informações do modelo logit.

Tabela 3. Modelo Logit

\begin{tabular}{ccccc}
\hline Parecer & Estimador & Erro & z-teste & Prob. \\
\hline EF & 0,0298 & 0,0104 & 2,8800 & 0,0040 \\
RVM & 0,0491 & 0,0115 & 4,2900 & 0,0000 \\
MDE & 0,1020 & 0,0307 & 3,3300 & 0,0010 \\
Constante & $-7,5021$ & 1,3468 & $-5,5700$ & 0,0000 \\
\hline
\end{tabular}

$\mathrm{N}^{\mathrm{o}}$ de observações $=664 ; \chi^{2}=50.32($ chi2 $) ; \operatorname{Prob}\left(\chi^{2}\right)=0,0000$

Fonte: Dados da pesquisa.

Para verificar a qualidade do ajustamento do modelo foi criada uma matriz de contingência (Tabela 4), que especifica o valor e determina se uma observação tem um resultado positivo previsto. Para isso, cada observação foi classificada como positiva se a sua probabilidade prevista for maior que 0,5 .

Tabela 4. Matriz de Contingência

\begin{tabular}{cccc}
\hline Classificação & Parecer Favorável (D) & Parecer Contrário ( D) & Total \\
\hline$(+)$ & 433 & 178 & 611 \\
$(-)$ & 9 & 44 & 53 \\
Total & $\mathbf{4 4 2}$ & $\mathbf{2 2 2}$ & $\mathbf{6 6 4}$ \\
\hline
\end{tabular}

Nota: Classificação Correta $=71,84 \%[(433+44) / 664]$

Fonte: Dados da pesquisa

Dentro dessa mesma lógica, conforme explicitado na Tabela 5, são apresentados os diversos cálculos probabilísticos a partir da matriz de contingência (Tabela 4). Segundo Corrar et al (2011), as observações superiores à predição de 0,5 são classificadas como positivas e as inferiores como negativas. Observa-se, na última linha que 
o modelo consegue classificar $71,84 \%$ das observações investigadas de forma correta.

Tabela 5. Probabilidade de Eventos

\begin{tabular}{ccc}
\hline Descrição & Argumento & Prob.(\%) \\
\hline Sensibilidade & $\operatorname{Pr}(+\mid \mathrm{D})$ & $97.96 \%$ \\
Especificidade & $\operatorname{Pr}(-\mid \sim \mathrm{D})$ & $19.82 \%$ \\
Valor preditivo positivo & $\operatorname{Pr}(\mathrm{D} \mid+)$ & $70.87 \%$ \\
Valor preditivo negativo & $\operatorname{Pr}(\sim \mathrm{D} \mid-)$ & $83.02 \%$ \\
Falso(+) para ( D) verdadeiro & $\operatorname{Pr}(+\mid \sim \mathrm{D})$ & $80.18 \%$ \\
Falso (-) para (D) verdadeiro & $\operatorname{Pr}(-\mid \mathrm{D})$ & $2.04 \%$ \\
Falso (+) classificado (+) & $\operatorname{Pr}(\sim \mathrm{D} \mid+)$ & $29.13 \%$ \\
Falso (-) classificado (-) & $\operatorname{Pr}(\mathrm{D} \mid-)$ & $16.98 \%$ \\
Classificação correta & & $71.84 \%$ \\
\hline
\end{tabular}

Nota: Classificação $(+)$ predição de $\operatorname{Pr}(\mathrm{D}) \geq 0,5$; Verdadeiro "D" definido como Parecer Fonte: Dados da pesquisa.

A respeito do modelo empírico consubstanciado na regressão logit, não é tão trivial a interpretação das estimativas dos coeficientes, porém, é indiscutível que o entendimento se deriva das estimativas sobre o sinal positivo ou negativo, da influência marginal do repressor em causa sobre a probabilidade de verificação do acontecimento, ou seja, o tipo de parecer.

No caso em tela, tem-se que todos os regressores apresentam-se significantes a $1 \%$ e que os sinais são todos positivos. Assim, percebe-se que não se rejeita a hipótese de que existe relação positiva entre o Parecer do TCE-PB emitido no julgamento das contas dos municípios e o nível de eficiência técnica na aplicação dos recursos públicos em educação fundamental.

Pelo que foi visto no modelo empírico, os pareceres prévios emitidos e encaminhados ao Poder Legislativo Municipal pelo Tribunal de Contas apresentam probabilidade dentro de uma relação direta com a eficiência da gestão municipal na aplicação dos recursos públicos direcionados à educação fundamental.

Verificou-se a magnitude e a relevância que a eficiência tem na emissão dos pareceres prévios das contas anuais dos municípios. Para isso, rodou-se o modelo calculando-se o efeito marginal. Os dados podem ser vistos na Tabela 6.

Tabela 6. Efeito Marginal do modelo Logit

\begin{tabular}{cccccc}
\hline Parecer & $\mathbf{d y} / \mathbf{d x}$ & Std. Err. & $\mathbf{z}$ & $\mathbf{P}>\mathbf{z}$ & $\mathbf{X}$ \\
\hline EF & 0,0065 & 0,0022 & 2,8900 & 0,0040 & 77,5694 \\
RVM & 0,0107 & 0,0025 & 4,3100 & 0,0000 & 63,9320 \\
MDE & 0,0222 & 0,0066 & 3,3500 & 0,0010 & 27,4578 \\
\hline
\end{tabular}

Nota: $\mathrm{y}=\operatorname{Pr}($ Parecer $)=0,67966557$

Fonte: Dados da pesquisa.

No modelo da Tabela 6, os coeficientes medem a variação no logit, estimado para uma variação unitária da variável explicada. Isso quer dizer que se o parecer for favorável, o logit aumenta. A probabilidade de uma conta ser aprovada no ponto médio é de $67,97 \%$. Neste caso, a probabilidade de uma conta ser aprovada, considerando o município mediano, é de cerca de $68 \%$, para essa amostra.

A probabilidade de uma conta anual ser aprovada aumenta em $0,65 \%$ para cada ponto percentual obtido na eficiência técnica. Assim, para um município que foi eficiente $(100 \%)$ a probabilidade de ter suas contas aprovadas é de $65 \%$.

No caso do FUNDEB, para cada ponto percentual aplicado, a probabilidade de uma conta anual ser aprovada aumenta em 1,07\%. Quanto ao MDE, as chances são acrescidas em 2,22\%. Dessa forma, o município que aplica em FUNDEB o mínimo constitucional de $60 \%$ tem a possibilidade de aprovação das contas de 
aproximadamente $28 \%(1,07 \times 60 \%)$. No que diz respeito ao MDE, essa probabilidade é de 55\% $(2,22 \times 25 \%)$. Fica evidenciado que esses valores são tomados isoladamente, ressaltando, por oportuno, que se o município aplicar menos do mínimo constitucional ele terá suas contas rejeitadas.

Tabela 7. Probabilidade de aprovação de contas sendo município eficiente

\begin{tabular}{cccccc}
\hline Parecer & $\mathbf{d y} / \mathbf{d x}$ & Std. Err. & $\mathbf{z}$ & $\mathbf{P}>\mathbf{z}$ & $\mathbf{X}$ \\
\hline EF & 0,0059 & 0,0015 & 4,0300 & 0,0000 & $100 \%$ \\
RVM & 0,0098 & 0,0026 & 3,7200 & 0,0000 & $60 \%$ \\
MDE & 0,0203 & 0,0067 & 3,0200 & 0,0030 & $25 \%$ \\
\hline
\end{tabular}

Nota: $\mathrm{y}=\operatorname{Pr}($ Parecer $)=0,72655$

Fonte: Dados da pesquisa.

Todavia, é necessário observar na Tabela 7 que, se o município aplica 25\% em MDE e 60\% dos recursos do FUNDEB em RMV, ele é eficiente (100\%), com isso a probabilidade de ter as contas aprovadas é de 72,66\%.

Tabela 8. Probabilidade de aprovação de contas sendo município ineficiente

\begin{tabular}{cccccc}
\hline Parecer & dy/dx & Std. Err. & $\mathbf{z}$ & $\mathbf{P}>\mathbf{z}$ & $\mathbf{X}$ \\
\hline EF & 0,0047 & 0,0003 & 14,8700 & 0,0000 & $20 \%$ \\
RVM & 0,0078 & 0,0033 & 2,3300 & 0,0200 & $60 \%$ \\
MDE & 0,0161 & 0,0067 & 2,3900 & 0,0170 & $25 \%$ \\
\hline
\end{tabular}

Nota: $\mathrm{y}=\operatorname{Pr}($ Parecer $)=0,19650$

Fonte: Dados da pesquisa.

Por outro lado, na Tabela 8, pode-se calcular a probabilidade de um município que cumpriu o mínimo constitucional em MDE (25\%) e em RVM (60\%); porém se ele ficou com um índice de eficiência de 20\%, a passa a ser de $19 \%$ a probabilidade de ter suas contas aprovadas. Ressalte-se que, como a decisão de julgamento de contas é colegiada, é possível que o Tribunal entenda que o não atingimento de um índice constitucional não seja motivo para reprovação de contas, dado que o município teve um bom desempenho na educação.

\section{CONSIDERAÇÕES FINAIS}

O presente estudo não buscou identificar os fatores que podem contribuir para o desenvolvimento da capacidade de um gestor lidar o com problema de ineficiência, mas desenvolver um modelo empírico definido a partir da técnica de regressão contendo uma variável dependente de natureza binária, para validar ou não a hipótese em causa.

O estudo utilizou o método de regressão binária simples para verificar a relação entre as variáveis eficiência técnica, RVM e MDE dos municípios paraibanos. Na estimativa do modelo logit, verificou-se que os coeficientes vistos conjuntamente são significativos para garantir a consistência do modelo, haja vista que a qualidade do modelo deve ser ajustada pela matriz de contingência. Para aumentar a robustez do modelo, utilizaram-se cálculos probabilísticos, os quais classificaram que $71,84 \%$ das observações foram investigadas de forma correta.

Ao interpretar as estimativas, comprovou-se que todos os coeficientes apresentam-se significativos a $1 \%$ com todos sinais positivos. É importante ressaltar, que no cálculo de efeito marginal ficou evidenciado que a probabilidade de uma conta ser aprovada no ponto médio é de $67,97 \%$. Neste sentido, o modelo mostrou que cada ponto percentual obtido na eficiência técnica, no FUNDEB e no MDE, acarretará em um aumento significativo de uma conta anual ser aprovada. Dito de outra forma, se o município segue os limites constitucionais e obtém um 
índice de eficiência de 100\% terá uma probabilidade de ter suas contas aprovadas em 72,66\%; em outro caso, se o município obtiver um índice de eficiência de $20 \%$, a probabilidade de emissão de um parecer favorável será de 19\%. Portanto, a eficiência técnica é um fator que afeta a probabilidade de uma conta ser favorável ou não.

Além disso, a análise das aplicações dos recursos públicos na MDE mostrou-se aderente ao tipo de parecer emitido pelo Tribunal de Contas. De modo semelhante, vislumbra-se uma relação direta e significativa na alocação dos recursos vinculados ao FUNDEB.

Pode-se então afirmar que com base nos resultados do estudo, não se rejeita a hipótese de pesquisa, validando-se que existe relação positiva entre o parecer do TCE-PB emitido no julgamento das contas dos municípios e o nível de eficiência técnica na aplicação dos recursos públicos na educação fundamental. Com isso, fica evidente que o TCE-PB pode interferir na dimensão da eficiência ou melhoria dos gastos públicos com educação fundamental.

Como limitações da presente pesquisa, destacam-se o período analisado e a inexistência de maior parte das informações nos anos posteriores a 2010, restringindo a amostra do cenário atual do Estado da Paraíba. Dessa forma, as conclusões emitidas ficam restritas à amostra estudada. Logo, essas limitações não invalidam os resultados obtidos.

Nota-se que o tema "eficiência dos gastos públicos" vem abrangendo crescentes discussões, merecendo colocar em destaque todos os resultados encontrados na hipótese desta pesquisa, visto que trazem significativas contribuições que podem ser úteis para os gestores de órgãos públicos, órgãos de controle e a sociedade como um todo. Diante disso, recomenda-se como estudos futuros, ampliar a amostra e incluir outras variáveis determinantes para aprovação de contas municipais por partes das Cortes de Contas.

\section{REFERÊNCIAS}

Ammons, D. N. (2003). Performance measurement and benchmarking in local government. In: Rabin, J. Encyclopedia of public administration and public policy. 2, Marcel Dekker: United Sates.

Banker, R. D., Charnes, A., \& Cooper, W. W. (1984). Some models for estimating technical scale inefficiencies in data envelopment analysis. Management Science. 30(9), pp. 1078-1092.

Belo, H. (2013). Audit committee's role in enhancing accountability of the Albanian public sector. European Journal of Business and Economics, 8(4).

Constituição da República Federativa do Brasil de 1988. (2015). Brasília, DF: Senado Federal.

Callahan, K. (2003). Performance measurement: citizen-driven. In: Rabin, J. Encyclopedia of public administration and public policy. 2, Marcel Dekker: United Sates.

Charnes, A., Cooper, W.W., Rhodes, E. (1978) Measuring the efficiency of decision-making units. European Journal of Operational Research, 2, p. 429-444.

Coleman, J. S., et al. (1966). Equality of education opportunity, GPO, Washington, DC.

Corrar, L. J. (2011). Análise multivariada: para os cursos de administração, ciências contábeis e economia. FIPECAPI - Fundação Instituto de pesquisas Contábeis, Atuariais e Financeiras; Luiz J. Corrar, Edílson Paulo, José Maria Dias Filho (coordenadores). São Paulo: Atlas.

Diniz, J. A., Corrar, L. J., \& Lima, S. C. (2014). A influência das transferências condicionais na eficiência da educação fundamental brasileira. In: VIII Congresso ANPCONT, Rio de Janeiro. Desenvolvimento tecnológico e evolução contábil.

Dourado, L. F., Oliveira, J. F., \& Santos, C. A. (2007). A qualidade da educação: conceitos e definições. Brasília, DF: INEP.

Freitas, L. R. (2013). Comparação das funções de ligação logit e probit em regressão binária considerando diferentes tamanhos amostrais. Tese (Doutorado) Universidade Federal de Viçosa.

Gualazzi, E. L. B. (1992). Regime jurídico dos tribunais de contas. São Paulo: Revista dos Tribunais.

Gujarati, D. N., \& Porter, D. C. (2011). Econometria básica. 5a ed. Porto Alegre: AMGH. 
Hair, J.R., et al. (1998). Multivariate analysis data. New Jersey: Princeton University Press.

Hanushek, E. A. (1986). The economics of schooling: production and efficiency in public schools. Journal of Economic Literature, 24, p. 1141-1177.

Hanushek, E. A. (1994). Money might matter somewhere: a response to Hedges, Laine, and Greenwald. Educational Researcher. May, 23(4), p. 5-8.

Haas, P. J. (2003). Performance indicators in state administration. In: Rabin, J. Encyclopedia of public administration and public policy. v.2, Marcel Dekker: United Sates.

Heinrich, C. J. (2003). Measuring public sector performance and effectiveness. In:. Peters, B. G. \& Pierre, J. The Sage Handbook of Public Administration. 2nd ed. London: Sage.

Herbest, F. G. (2010). Regime de competência no setor público: a experiência de implementação em diversos países. Dissertação. (Mestrado em Ciências Contábeis). Programa de Pós Graduação em Ciências Contábeis - Fundação Instituto Capixaba de Pesquisa em Contabilidade, Economia e Finanças (FUCAPE).

Julnes, P. de L. (2003). Performance measuremente. In: Rabin, J. Encyclopedia of public administration and public policy. 2, Marcel Dekker: United States.

Lopes, A. B. (2009). Sistema de Informação de gestão econômica. In: Filho, J. F. R., Lopes, J., \& Perderneiras, M. (Org.). Estudando Teoria da Contabilidade. São Paulo: Atlas.

Loureiro, M. R., Teixeira, M.A. C., \& Moraes, T.C. (2009). Democratização e reforma do Estado: o desenvolvimento institucional dos tribunais de contas no Brasil recente. Revista de Administração Pública, 43(4), pp. 739-72.

Martins, G. A., \& Theóphilo, C. R. (2007). Metodologia da investigação científica para ciências sociais aplicadas. São Paulo: Atlas.

Menezes Filho, N. A., \& Amaral, L. F. L. E. (2009). A relação entre gastos educacionais e desempenho escolar. IBMEC, São Paulo, Working Papers, n. 162.

Mendes, M. (2003). A eficácia da vinculação de recursos no federalismo brasileiro: o caso do FUNDEF. In: Finanças Públicas. VIII Prêmio do Tesouro Nacional. Brasília: Universidade de Brasília.

Oliveira, C. E. M., \& Turrioni, J. B. (2006). Medidas de desempenho na gestão pública: estudo de caso em uma instituição federal de ensino superior. Anais do IX Simpósio de Administração da Produção, Logística e Operações Internacionais. SIMPOI.

Pacheco, R. S. (2009). Mensuração de desempenho no setor público: os termos do debate. Cadernos Gestão Pública e Cidadania, FGV de Periódicos e Revistas, 14(55).

Pritchett, L., \& Filmer, D. (1999). What education production functions really show: a positive theory of education spending. Economics of Education Review, 18(2), pp. 223-239.

Samuelson, P. A. (1954). The pure theory of public expenditure. Review of economics and Statistics, Massachusetts, 36, pp. 387-389.

Silva, C. A. T., \& Revorêdo, W. C. (2005). Economicidade da gestão pública municipal: um estudo das decisões do tribunal de contas do Estado de Pernambuco. Revista Universo Contábil, 1(2), pp. 09-2.

Tabachnick, B. G., \& Fidell. L. S. (1996). Using multivariate statistics. 4 ed., California State University, Northridge.

Torres, M. D. F. (2004). Estado, democracia e administração pública no Brasil. Rio de Janeiro: Editora FGV.

Weffort, E. F. J. (2005). O Brasil e a harmonização contábil: Influências dos sistemas jurídicos e educacional, da cultura e do mercado. São Paulo: Atlas. 